\title{
Steroid responsive cavernous sinus syndrome due to Rosai-Dorfman disease: beyond Tolosa-Hunt syndrome - a case report
}

\author{
Paulo Ribeiro Nóbrega ${ }^{1 *}$, Pedro Gustavo Barros Rodrigues', Isabelle de Sousa Pereira', \\ Carolina de Figueiredo Santos², Gunter Gerson³, José Arnaldo Motta de Arruda ${ }^{4}$, \\ José Wagner Leonel Tavares Júnior ${ }^{1}$, Pablo Picasso de Araújo Coimbra ${ }^{5}$ and Pedro Braga-Neto ${ }^{1,6}$
}

\begin{abstract}
Background: The term "Tolosa-Hunt syndrome" (THS) has been used to refer to painful ophthalmoplegia associated with nonspecific inflammation of the cavernous sinus and many processes can result in a similar clinical picture, including infectious, inflammatory and neoplastic diseases. Rosai-Dorfman disease (RDD) is a lymphoproliferative disorder that rarely affects the central nervous system. We report a case of isolated CNS RosaiDorfman disease involving the cavernous sinus and presenting as "Tolosa-Hunt syndrome".

Case presentation: Our patient presented with horizontal diplopia due to impairment of cranial nerves III, IV and VI and a stabbing/throbbing headache predominantly in the left temporal and periorbitary regions. There was a nonspecific enlargement of the left cavernous sinus on MRI and the patient had a dramatic response to steroids. Biopsy of a frontal meningeal lesion was compatible with RDD.
\end{abstract}

Conclusions: We highlight the importance of including Rosai-Dorfman disease as a differential diagnosis in cavernous sinus syndrome and demonstrate a satisfactory long-term response to steroid treatment in this disease.

Keywords: Rosai-Dorfman Disease, Histiocytosis, Tolosa-Hunt Syndrome, Cavernous Sinus, Neuroimmunology, Case report

\section{Background}

The eponym "Tolosa-Hunt syndrome" (THS) was first used in 1966 referring to painful ophthalmoplegia associated with nonspecific inflammation of the cavernous sinus [1] and it remains a diagnosis of exclusion. It is a rare condition that affects one in one million people worldwide and many pathological processes can result in

\footnotetext{
*Correspondence: paulo_r_med@yahoo.com.br

'Division of Neurology, Department of Clinical Medicine, Universidade Federal do Ceará, Rua Capitão Francisco Pedro, 1290, 60430-370 Fortaleza, Brazil

Full list of author information is available at the end of the article
}

a similar clinical picture, including infectious, inflammatory and neoplastic diseases [2]. Some of the diseases that mimic THS may present a rapid response to steroids, which led to some authors calling for a retirement of the diagnostic eponym [3]. as it could be often misleading and postpone a diagnosis of a potentially lifethreatening condition.

Rosai-Dorfman disease (RDD) is a lymphoproliferative disorder of unknown etiology. It is characterized by nonmalignant overproduction and accumulation of histiocytes in the lymph nodes and extra-nodal tissue. This disease has an incidence of approximately 100 new cases

(C) The Author(s). 2021 Open Access This article is licensed under a Creative Commons Attribution 4.0 International License, which permits use, sharing, adaptation, distribution and reproduction in any medium or format, as long as you give appropriate credit to the original author(s) and the source, provide a link to the Creative Commons licence, and indicate if changes were made. The images or other third party material in this article are included in the article's Creative Commons licence, unless indicated otherwise in a credit line to the material. If material is not included in the article's Creative Commons licence and your intended use is not permitted by statutory regulation or exceeds the permitted use, you will need to obtain permission directly from the copyright holder. To view a copy of this licence, visit http://creativecommons.org/licenses/by/4.0/. The Creative Commons Public Domain Dedication waiver (http://creativecommons.org/publicdomain/zero/1.0/) applies to the data made available in this article, unless otherwise stated in a credit line to the data. 
per year in the United States [4-9] and affects the central nervous system (CNS) in less than $5 \%$ of cases. Most of these cases have isolated CNS involvement (> $80 \%$ ) and over $90 \%$ involve the intracranial compartment $[4,10,11]$, usually presenting as meningeal lesions that resemble meningiomas $[11,12]$. We report a case of isolated CNS Rosai-Dorfman disease involving the cavernous sinus and presenting as "Tolosa-Hunt syndrome" with a dramatic response to steroids.

\section{Case presentation}

A 38-year-old male patient presented with horizontal diplopia, divergent strabismus and ptosis of the left eyelid. He also had an intense stabbing/throbbing headache predominantly in the left temporal and periorbitary regions. Headache was continuous and demonstrated little response to common analgesics and nonsteroidal antiinflammatories (NSAIDs). There was no complaint of nausea, vomiting, phonofobia or photophobia. The patient also complained of numbness in his left frontal and upper face (territory of ophthalmic and maxillary divisions of the trigeminal nerve).

There was a previous history of right-sided focal motor seizures, and a previous brain surgery 10 years ago for resection of a low grade tumour of the left frontal lobe (there was no pathological or immunohistochemistry report of that surgery available).

On examination the patient had complete third nerve palsy, sixth nerve palsy and loss of pinprick and thermic sensations in the territories of the Ophtalmic (V1) and Maxillary (V2) divisions of the trigeminal nerve on the left side. Other parts of the neurological examination, including cognition, motricity, reflexes and coordination were normal. There was no papilledema.

A clinical diagnosis of cavernous sinus syndrome was made, and the patient was started on prednisone $60 \mathrm{mg} /$ day, with significant improvement of headache intensity, resolution of ptosis and improvement in adduction, elevation and partial improvement in abduction of the left eye. An additional movie file shows this in more detail [see Additional file 1].

Brain magnetic resonance imaging (MRI) revealed an asymmetry of the cavernous sinuses, with the left cavernous sinus being larger than the right (Fig. 1). There were also four meningeal lesions with contrast enhancement and without calcification in the upper convexity adjacent to the left and right frontal lobes, in the left cerebellopontine angle and left posterior temporal region (Fig. 2).A biopsy of the meningeal lesion in the frontal convexity was performed, and resulted in a meningeal fragment with histiocytic proliferation (Fig. 3). Immunohystochemical profile was negative for CD1a and ALK-1 and was positive for S100, CD68 (KP1 clone) and EMA (E29 clone), compatible with Rosai-Dorfman disease. Whole body computerized tomography (CT) scans did not reveal any other masses or lymphadenomegalies, characterizing an isolated CNS Rosai-Dorfman disease.

The patient was treated with intravenous methylprednisolone $1 \mathrm{~g} / \mathrm{kg}$ daily for five days, with significant improvement of the cavernous sinus syndrome. Maintenance treatment consisted of prednisone $10 \mathrm{mg} /$ day after tapering. He is asymptomatic and has remained seizure-free for two years. Follow-up brain MRI has showed a decrease in size of meningeal lesions and of cavernous sinus asymmetry (Fig. 4).

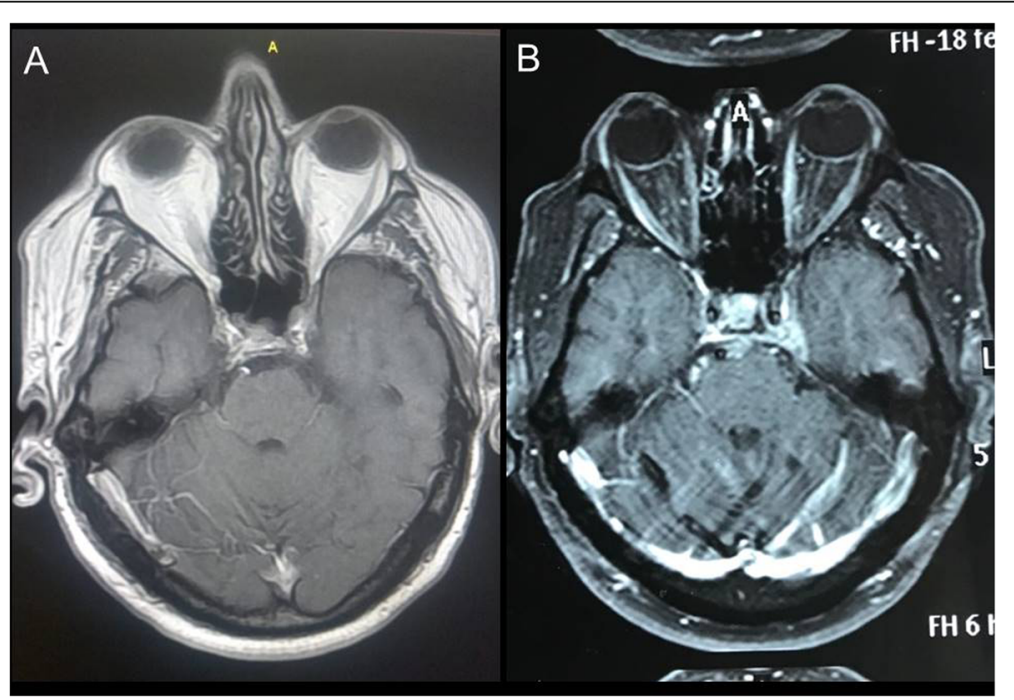

Fig. 1 Neuroimaging findings in the patient with Rosai-Dorfman disease demonstrating: asymmetry of the cavernous sinuses in $T 1$, with the left cavernous sinus larger than the right, and contrast enhancement of the left cavernous sinus 


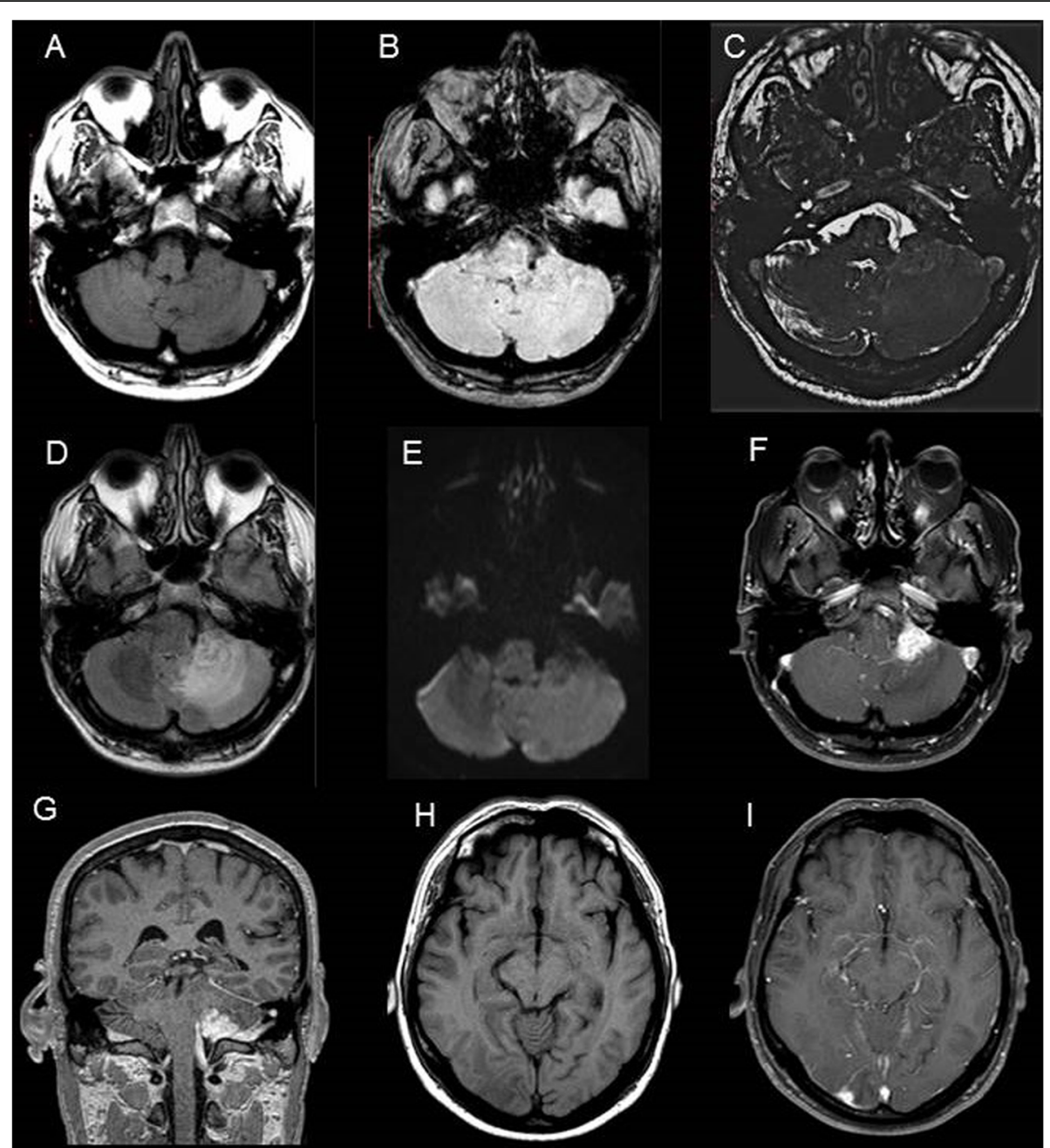

Fig. 2 Neuroimaging findings in the patient with Rosai-Dorfman disease demonstrating extra-axial nodular image located in the left cerebellopontine angle cistern with isosignal in T1 and low signal in T2 / FLAIR with homogeneous contrast enhancement, surrounded by cerebellar edema, with dural tail and no restricted diffusion (A, B to $\mathbf{G}$ ). In $\mathbf{H}$ and $\mathbf{I}$ there is a small extra-axial image with the same characteristics described above in the right temporal region

\section{Discussion and conclusions}

The term "Tolosa-Hunt syndrome" has been used to describe a syndrome of painful ophthalmoplegia characterized by periorbital or hemicranial pain associated with ipsilateral ocular motor nerve (third, fourth and sixth cranial nerves) palsies, oculosympathetic impairment, and trigeminal sensory loss in the distribution of the ophthalmic and/or maxillary divisions [2].

The disease is believed to be related to a non-specific inflammatory process in the region of the cavernous sinus and have a relapsing and remitting course with prompt response to systemic corticosteroid therapy [2]. There is an extensive and growing list of differential diagnoses, including IgG4-related disease [13], many of which may respond rapidly to steroids. Thus, the clinical picture, neuroimaging and even a dramatic response to steroids are not specific, and it remains a diagnosis of exclusion. Incorrect use of the eponym could therefore result in missing infective or neoplastic conditions and delaying appropriate treatment [3].

We described a patient which fulfilled the International Classification of Headache Disorders (ICHD) criteria for THS (Table 1) [14] and was found to have isolated CNS Rosai-Dorfmann disease.

Rosai-Dorfman disease, or Sinus Histiocytosis with Massive Lymphadenopathy, was first described in 1969 by Rosai and Dorfman [8]. Its clinical presentation is very heterogenous and depends on the affected body sites, but it usually presents with bilateral, massive and painless cervical lymphadenopathy that might be associated with fever, weight loss, night sweats, polyclonal hypergammaglobulinemia, high erythrocyte sedimentation rate and leukocytosis $[5-9,15]$. The most common extra-nodal sites are skin, orbit and eyelid, bone, central nervous system and upper respiratory tract $[5-7,11$, 15-17]. Biopsy reveals accumulation of histiocytes 

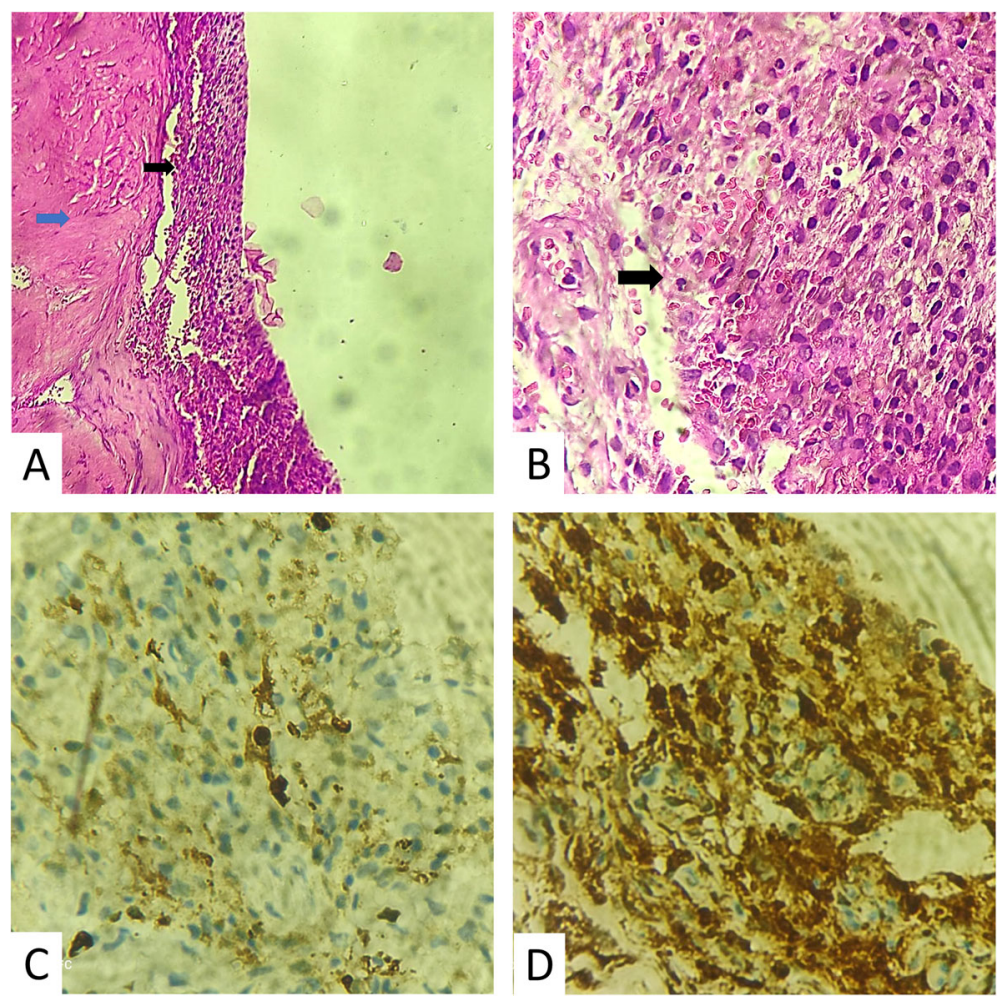

Fig. 3 A- HE staining, 10x low magnification: Histological specimen show sections of fibrous and thickened dura mater (blue arrow) with extensive superficial infiltration by histiocytic cells (black arrow). B - HE staining, 20x intermediate magnification Histological sections show extensive superficial meningeal infiltration by histiocytes ( arrow ); absence of cell atypias, malignant cells or meningothelial neoplasia. C Immunohistochemical reaction for CD68: diffuse positivity in lesion cells, confirming histiocytic aspect. D - Immunohistochemical reaction for S100: focal positivity in lesion cells, confirming histiocytic aspect. Other reactions performed were negative: CD1a and ALK (not shown)

positive for S-100 protein and for $\mathrm{CD} 68$, and negative for CD1a on immunohistochemical examination [5-7]. Emperipolesis can occur, which consists in the presence of intact hematopoietic cells (mostly lymphocytes) inside histiocytes $[5-7,15]$. This is a typical feature of systemic $\mathrm{RDD}$, but may not always be present in isolated CNS disease [18].

Intracranial Rosai-Dorfman disease typically involves the meninges, presenting as an enhancing dural-based lesion with surrounding vasogenic edema mimicking a meningioma [19], which was also the case with our patient. It usually shows isointensity on T1-weighted MRI and isointensity with areas of hypointensity on T2-weighted or FLAIR imaging [19]. A dural tail is present in most cases, being absent in a single case report [20]. It has been suggested that the absence of internal calcification or haemorrhage on $\mathrm{CT}$ and the presence of areas of low intensity within the lesion on T2-weighted MRI can help in differentiating meningeal RDD from a meningioma [19, 20]. It may also eventually resemble lymphomas or metastases and biopsy is necessary for a histopathological diagnosis to be confirmed [17].
Symptoms of intracranial Rosai-Dorfman disease vary according to the site of the meninges affected. Headaches, seizures and focal neurological deficits due to mass effect and edema are the most common neurological symptoms, but cranial nerve dysfunction, cognitive decline and pituitary dysfunction may also occur [11].

In a recent review $\mathrm{Li}$ et al. found 12 previously published cases of RDD involving the cavernous sinus [10, $12,29,30,21-28]$, but none of them reported fulfilling clinical criteria for THS, including a dramatic response to steroids [30]. This case report supports the inclusion of Rosai-Dorfman Disease in the extensive list of differential diagnoses for painful ophtalmoplegia syndrome.

The best strategy for management of primary CNS RDD is still uncertain, therefore treatment is aligned with the individualities of each case. Therapy can vary from surgery, corticosteroids, serolimus, radiotherapy, chemotherapy or immunomodulation. Surgery is considered the best option for unifocal disease or cases with symptomatic sinus, airway, cranial or spinal disease [9] and it has been suggested that radical resection should be the ideal surgical goal $[15,17,31,32]$. In some cases, 


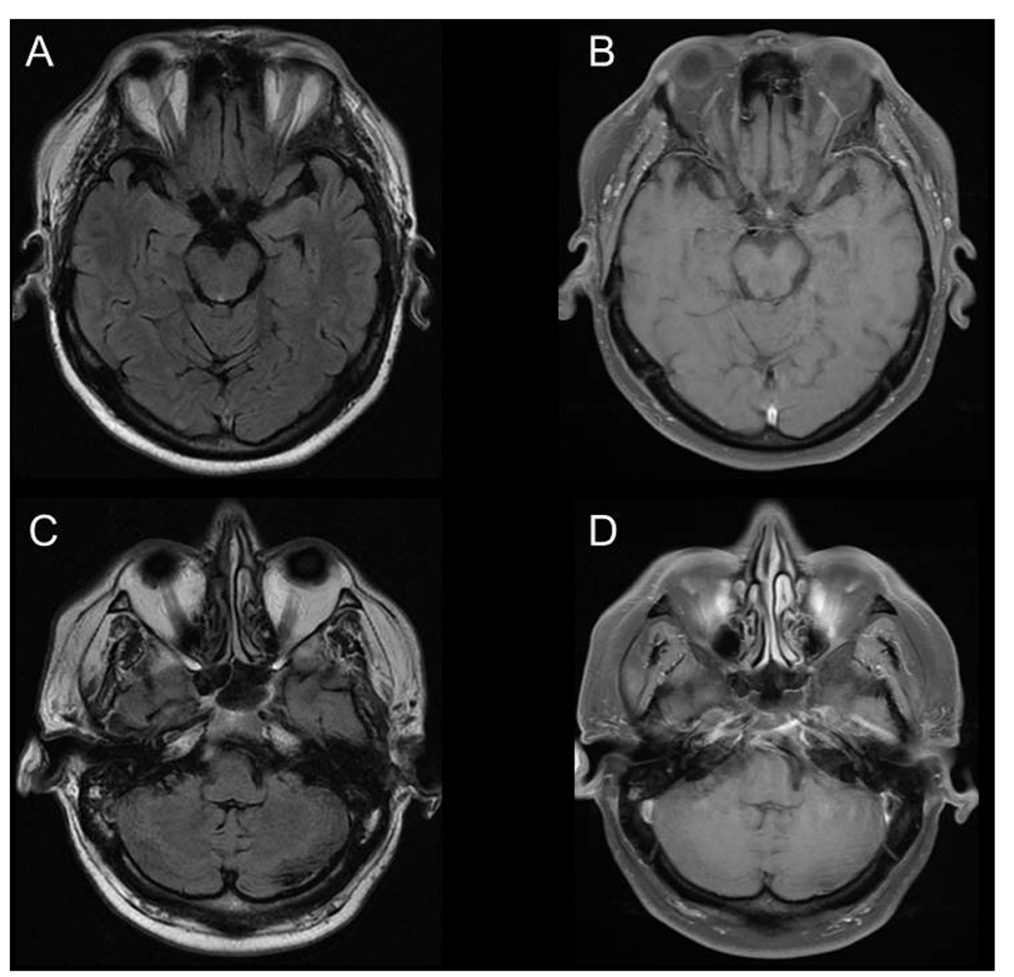

Fig. 4 Neuroimaging findings in the patient with Rosai-Dorfman disease one year after the first examination demonstrating disappearance of the extra-axial nodular image located in the left cerebellopontine angle cistern and the right temporal region, as well as resolution of cavernous sinus asymmetry

Table 1 International Classification of Headache Disorders (ICHD-3) criteria for Tolosa-Hunt syndrome

\section{DESCRIPTION}

Unilateral orbital and periorbital pain associated with paresis of one or more of the third, fourth or sixth cranial nerves caused by a

granulomatous inflammation in the cavernous sinus, superior orbital fissure or orbit.

\section{DIAGNOSTIC CRITERIA}

A. Unilateral orbital or periorbital headache fulfilling criterion $C$.

\section{B. Both of the following:}

1. Granulomatous inflammation of the cavernous sinus, superior orbital

fissure or orbit, demonstrated by MR scan or biopsy.

2. Paresis of one or more of the ipsilateral third, fourth and/or sixth cranial nerves.

\section{Evidence of causation demonstrated by both of the following:}

1. Headache is ipsilateral to the granulomatous lesion.

2. Headache has preceded paresis of the third, fourth and/or sixth nerves by $\leq 2$ weeks or developed with it.

\section{Not better accounted for by another ICHD-3 diagnosis.}

Comments:

Some reported cases of 13.8 Tolosa-Hunt syndrome had additional involvement of the fifth nerve (commonly the first division) or optic, seventh or eighth nerves. Sympathetic innervation of the pupil is occasionally affected.

Careful follow-up is required to exclude other causes of painful ophthalmoplegia such as tumours, vasculitis, basal meningitis, sarcoidosis or diabetes mellitus.

Pain and paresis of 13.8 Tolosa-Hunt syndrome resolve when it is treated adequately with corticosteroids. however, the lesions may invade or surround critical structures, such as the cavernous sinus in our case, the carotid artery, or adhere to the brain cortex, and may not be completely resectable. Response to steroids has been variable and often incomplete in previous reports $[15,32]$. A recently published case of isolated meningeal RDD found complete remission with low-dose steroids [33]. The patient reported here had a dramatic response to steroids and remission was maintained after tapering with low-dose steroids for a prolonged time.

The definitive diagnosis in patients suspected to have "Tolosa-Hunt syndrome" is challenging as in many of these cases a potentially life-threatening disease may be the actual cause of the symptoms. We highlight in this case report the need to include Rosai-Dorfman disease as a differential diagnosis in cavernous sinus syndrome.

\section{Abbreviations}

CT: Computerized tomography.; CNS: Central nervous system.; ICHD: International Classification of Headache Disorders.; MRI: Magnetic resonance imaging.; NSAIDs: Nonsteroidal anti-inflammatories drugs.; RDD: Rosai-Dorfman disease.; THS: Tolosa-Hunt syndrome.

\section{Supplementary information}

The online version contains supplementary material available at https://doi. org/10.1186/s12883-021-02255-z. 
Additional file 1. Neurological examination in a patient with cavernous sinus syndrome due to Rosai-Dorfman disease after pulsed steroid therapy demonstrating left sixth nerve palsy.

\section{Acknowledgements \\ Not applicable.}

\section{Authors' contributions}

Conception of the work - PRN, PGBR, ISP, CFS. Drafting the work - PRN, PGBR, ISP, CFS, JWLTJ. Acquisition of the data - PRN, GG, JAMA, JWLTJ, PPAC. Analysis and interpretation of data for the work - PRN, GG, JWLTJ, PBN. Design of the work - PRN, JWLTJ, PBN. Revising the work critically - GG, JAMA, JWLTJ, PPAC, PBN. Final approval of the version to be published and agreement to be accountable for all aspects of the work - all authors.

\section{Fundings}

We have nothing to disclose.

\section{Availability of data and materials}

Not applicable.

\section{Declarations}

Ethics approval and consent to participate

Not applicable.

\section{Consent for publication}

Written informed consent was obtained from the patient for publication of this case report and any accompanying images, including the reproduction of partially identifiable photographs. A copy of the written consent is available for review by the Editor of this journal.

\section{Competing interest}

On behalf of all authors, the corresponding author states that there is no conflict of interest

\section{Author details}

'Division of Neurology, Department of Clinical Medicine, Universidade Federal do Ceará, Rua Capitão Francisco Pedro, 1290, 60430-370 Fortaleza, Brazil. ${ }^{2}$ Hospital Infantil Albert Sabin, Fortaleza, Brazil. ${ }^{3}$ Department of Pathology, Universidade Federal do Ceará, Fortaleza, Brazil. ${ }^{4}$ Division of Neurosurgery, Department of Surgery, Universidade Federal do Ceará, Fortaleza, Brazil. ${ }^{5}$ Uniclinic Diagnóstico por Imagem - UDI Fortaleza, Fortaleza, Brazil. ${ }^{6}$ Center of Health Sciences, Universidade Estadual do Ceará, Fortaleza, Brazil.

\section{Received: 27 January 2021 Accepted: 26 May 2021}

Published online: 05 July 2021

\section{References}

1. Smith JL, Taxdal DS. Painful ophthalmoplegia. The Tolosa-Hunt syndrome. Am J Ophthalmol. 1966;61(6):1466-1472. Accessed February 27, 2020. http:// www.ncbi.n/m.nih.gov/pubmed/5938314.

2. Kline LB, Hoyt WF. The Tolosa-Hunt syndrome. J Neurol Neurosurg Psychiatry. 2001;71(5):577-82. doi:https://doi.org/10.1136/jnnp.71.5.577.

3. Lueck CJ. Time to retire the Tolosa-Hunt syndrome? Pract Neurol. 2018. 18(5):350-1. doi:https://doi.org/10.1136/practneurol-2018-001951.

4. Kozak B, Talbott J, Uzelac A, Rehani B. Rosai-Dorfman disease isolated to the thoracic epidural spine. J Radiol Case Rep. 2015;9(11):6-16. doi:https://doi. org/10.3941/jrcr.v9i11.2629.

5. Emile JF, Abla O, Fraitag S, et al. Revised classification of histiocytoses and neoplasms of the macrophage-dendritic cell lineages. Blood. 2016;127(22): 2672-81. doi:https://doi.org/10.1182/blood-2016-01-690636.

6. Haroche J, Cohen-Aubart F, Rollins BJ, et al. Histiocytoses: emerging neoplasia behind inflammation. Lancet Oncol. 2017;18(2):e113-25. doi: https://doi.org/10.1016/S1470-2045(17)30031-1.

7. Rosai J. Lymph node. Rosai and Ackerman's Surgical Pathology. 9th ed. Mosby; 2004.
8. Rosai J, Dorfman RF. Sinus histiocytosis with massive lymphadenopathy. A newly recognized benign clinicopathological entity. Arch Pathol. 1969;87(1):63-70.

9. Abla O, Jacobsen E, Picarsic J, et al. Consensus recommendations for the diagnosis and clinical management of Rosai-Dorfman-Destombes disease. Blood. 2018;131(26): 2877-90. doi:https:/doi.org/10.1182/blood-2018-03-839753.

10. Sandoval-Sus JD, Sandoval-Leon AC, Chapman JR, et al. Rosai-dorfman disease of the central nervous system: Report of 6 cases and review of the literature. Med (United States). 2014;93(3):165-75. doi:https://doi.org/10.1 097/MD.0000000000000030.

11. Adeleye AO, Amir G, Fraifeld S, Shoshan Y, Umansky F, Spektor S. Diagnosis and management of rosai-dorfman disease involving the central nervous system. Neurol Res. 2010;32(6):572-8. doi:https:/doi.org/10.1179/016164109X12608733393836.

12. Yang $X$, Liu J, Ren Y, Richard SA, Zhang Y. Isolated intracranial RosaiDorfman disease mimicking petroclival meningioma in a child. Med (United States). 2017:96(47):e8754. https://doi.org/10.1097/MD.0000000000008754.

13. Lee CS, Harocopos GJ, Kraus CL, et al. IgG4-associated orbital and ocular inflammation. J Ophthalmic Inflamm Infect. 2015;5:15. https://doi.org/10.11 86/s12348-015-0047-y.

14. Olesen J, Bes A, Kunkel R, et al. The International Classification of Headache Disorders, 3rd edition. Cephalalgia. 2013;33(9):629-808. doi:https://doi.org/1 $0.1177 / 0333102413485658$

15. Foucar E, Rosai J, Dorfman R. Sinus histiocytosis with massive lymphadenopathy (Rosai-Dorfman disease): Review of the entity. Semin Diagn Pathol. 1990;7(1):19-73.

16. Lutterbach J, Henne K, Pagenstecher A, Böhm J. Lung cancer and RosaiDorfman's disease: A clinicopathological study. Strahlentherapie Onkol. 2003;179(7):486-92. doi:https://doi.org/10.1007/s00066-003-1032-1.

17. Tan S, Ruan L, Jin K, et al. Systemic Rosai-Dorfman disease with central nervous system involvement. Int J Neurosci. 2018;128(2):192-7. doi:https:// doi.org/10.1080/00207454.2017.1377709.

18. Jaffe ES, Arber DA, Campo E, Harris NL, Quintanilla-Martinez L. Hemopathology. 2nd ed.: Elsevier; 2016.

19. Zhu H, Qiu LH, Dou YF, et al. Imaging characteristics of Rosai-Dorfman disease in the central nervous system. Eur J Radiol. 2012;81(6):1265-72. doi: https://doi.org/10.1016/j.ejrad.2011.03.006.

20. Alimli AG, Oztunali C, Boyunaga OL, Pamukcuoglu S, Okur A, Borcek AO. MR and CT findings of isolated intracranial Rosai-Dorfman disease in a child. Neuroradiol J. 2016;29(2):146-9. doi:https://doi.org/10.1177/1971400915628020.

21. Lopez P, Estes ML. Immunohistochemical characterization of the histiocytes in sinus histiocytosis with massive lymphadenopathy: Analysis of an extranodal case. Hum Pathol. 1989;20(7):711-5. doi:https://doi.org/10.1016/0046-8177(89)90162-7.

22. Shaver EG, Rebsamen SL, Yachnis AT, Sutton LN. Isolated extranodal intracranial sinus histiocytosis in a 5-year-old boy. Case report. J Neurosurg. 1993;79(5):769-73. doi:https://doi.org/10.3171/jns.1993.79.5.0769.

23. Hadjipanayis CG, Bejjani G, Wiley C, Hasegawa T, Maddock M, Kondziolka D. Intracranial Rosai-Dorfman disease treated with microsurgical resection and stereotactic radiosurgery: Case report. J Neurosurg. 2003;98(1 SUPPL.):165-8. doi:https://doi.org/10.3171/jns.2003.98.1.0165.

24. Türe U, Şeker A, Bozkurt SU, Üneri C, Sav A, Pamir MN. Giant intracranial Rosai-Dorfman disease. J Clin Neurosci. 2004;11(5):563-6. doi:https://doi. org/10.1016/j.jocn.2003.11.012.

25. Rodriguez-Galindo C, Helton KJ, Sánchez ND, Rieman M, Jeng M, Wang W Extranodal Rosai-Dorfman Disease in Children. J Pediatr Hematol Oncol. 2004;26(1):19-24. doi:https://doi.org/10.1097/00043426-200401000-00007.

26. Kaminsky J, Koerbel A, Mittelbronn M, Beschorner R, Ernemann U, Tatagiba M. Rosai-Dorfman disease involving the cranial base, paranasal sinuses and spinal cord. Clin Neuropathol. 2005;24(4):194-200. Accessed 27 August 2020 https://europepmc.org/article/med/16033137.

27. Sundaram C, Uppin SG, Prasad BCM, et al. Isolated Rosai Dorfman disease of the central nervous system presenting as dural-based and intraparenchymal lesions. Clin Neuropathol. 2005;24(3):112-117. Accessed 27 August 2020. https://europepmc.org/article/med/15943162.

28. Gupta DK, Suri A, Mahapatra AK, et al. Intracranial Rosai-Dorfman disease in a child mimicking bilateral giant petroclival meningiomas: A case report and review of literature. Child's Nerv Syst. 2006;22(9):1194-200. doi:https:// doi.org/10.1007/s00381-006-0055-1.

29. Hinduja A, Aguilar LG, Steineke T, Nochlin D, Landolfi JC. Rosai-Dorfman disease manifesting as intracranial and intraorbital lesion. J Neurooncol. 2009;92(1):117-20. doi:https://doi.org/10.1007/s11060-008-9733-z. 
30. Li Z, Zhou C, Chen G, Bao Y. Intracranial Rosai-Dorfman Disease Involving the Cavernous Sinus: A Case Report and Review of the Literature. World Neurosurg. 2018;119:249-55. doi:https://doi.org/10.1016/j.wneu.2018.08.031.

31. Pham CB, Abruzzo LV, Cook E, Whitman GJ, Stephens TW. Rosai-Dorfman disease of the breast. Am J Roentgenol. 2005;185:971-2. doi:https://doi. org/10.2214/AJR.05.0224.

32. Oka M, Kamo T, Goto N, et al. Successful treatment of Rosai-Dorfman disease with low-dose oral corticosteroid. J Dermatol. 2009;36(4):237-40. doi:https://doi.org/10.1111/j.1346-8138.2009.00630.x.

33. Bezerra Lima L, Alves Sobreira-Neto M, Braga-Neto P, Ribeiro Nóbrega P. Isolated central nervous system Rosai-Dorfman disease and breast cancer: an unusual presentation. Int J Neurosci. 2019;129(4):393-6. doi:https://doi. org/10.1080/00207454.2018.1533823.

\section{Publisher's Note}

Springer Nature remains neutral with regard to jurisdictional claims in published maps and institutional affiliations.

Ready to submit your research? Choose BMC and benefit from:

- fast, convenient online submission

- thorough peer review by experienced researchers in your field

- rapid publication on acceptance

- support for research data, including large and complex data types

- gold Open Access which fosters wider collaboration and increased citations

- maximum visibility for your research: over $100 \mathrm{M}$ website views per year

At BMC, research is always in progress.

Learn more biomedcentral.com/submissions 